\title{
Activité virucide in vitro d'un extrait de cyprès sur des virus humains et bovins
}

\section{In vitro Virucidal Activity of an Extract of Cypress on Human and Bovine Viruses}

\author{
I. Guinobert - V. Bardot - L. Berthomier $\cdot$ I. Ripoche $\cdot$ C. Faivre $\cdot$ L. Haddioui $\cdot$ H. Belkhelfa \\ (C) Lavoisier SAS 2018
}

\begin{abstract}
Résumé L'objectif était de réaliser l'empreinte phytochimique par HPTLC et d'identifier par LC/MS les principaux composés d'un extrait hydroéthanolique de cônes frais de cyprès (Cupressus sempervirens L.) puis d'évaluer l'activité virucide de cet extrait sur quatre virus infectant l'Homme et trois virus bovins. L'analyse phytochimique a montré la présence de tanins, de flavonoïdes, d'acides aminés et de glucides. À $40 \%(\mathrm{v} / \mathrm{v})$, au contact des virus pendant 60 minutes à $37^{\circ} \mathrm{C}$, l'extrait a eu une activité virucide sur le coronavirus, le virus parainfluenza de type 3, le virus respiratoire syncytial bovin et le rotavirus bovin. À $80 \%$ (v/v), l'extrait a eu une activité virucide sur le virus influenza A-H1N1, le rhinovirus et l'herpèsvirus bovin de type 1 . Ces résultats invitent à poursuivre les travaux sur cet extrait de cyprès et à explorer ses effets antiviraux in vivo.
\end{abstract}

Mots clés Cyprès · Proanthocyanidines · Tanins · Virus · Activité virucide

\begin{abstract}
The aim of this study was to carry out HPTLC (high-performance thin-layer chromatography) fingerprinting analysis and to identify by LC/MS (liquid chromatogra-
\end{abstract}

I. Guinobert $(\bowtie) \cdot$ V. Bardot

Groupe PiLeJe, 37, quai de Grenelle,

F-75015 Paris cedex 15, France

e-mail : i.guinobert@pileje.com

Naturopôle, Les Tiolans,

F-03800 Saint-Bonnet-de-Rochefort, France

L. Berthomier · I. Ripoche

CNRS, Sigma Clermont, institut de chimie de Clermont-Ferrand, université Clermont-Auvergne, BP 10448,

F-63000 Clermont-Ferrand, France

C. Faivre

Wamine, 20, rue du Docteur-Finlay,

F-75738 Paris cedex 15, France

L. Haddioui · H. Belkhelfa

Laboratoire Fonderephar, faculté de pharmacie,

35, chemin des Maraîchers, F-31062 Toulouse cedex 04, France phy-mass spectrometry) the main components of a hydroethanolic extract of cypress (Cupressus sempervirens L.) fresh cones; the study also aimed at evaluating the extract's virucidal activity against four human viruses and three bovine viruses. The phytochemical analysis showed the presence of tannins, flavonoids, amino acids, and carbohydrates. At $40 \%(\mathrm{v} / \mathrm{v})$ concentration, in contact with viruses for 60 minutes at $37^{\circ} \mathrm{C}$, the extract had virucidal activity against coronavirus, parainfluenza type 3 virus, bovine respiratory syncytial virus, and bovine rotavirus. At $80 \%(\mathrm{v} / \mathrm{v})$, the extract had virucidal activity against influenza A-H1N1 virus, rhinovirus, and bovine herpes type 1 virus. These results show that it would be worthwhile to pursue research on this cypress extract and to explore its antiviral effects in vivo.

Keywords Cypress · Proanthocyanidins · Tannins · Virus · Virucidal activity

\section{Introduction}

La lutte contre les virus respiratoires est un enjeu majeur de santé publique qui nécessite de développer à la fois des stratégies préventives et curatives [1]. Des résistances et des virus hybrides ne cessent d'émerger, et les traitements antiviraux ne sont pas toujours efficaces ni bien tolérés [2-8]. Par ailleurs, il y a une relation entre les infections virales et la survenue d'infections bactériennes - comme, par exemple, les surinfections pulmonaires à pneumocoque dans un contexte d'infection grippale [9] — qui requièrent des antibiothérapies concourant aussi à faire émerger des résistances, dans ce cas, au niveau des souches bactériennes auxquelles sont exposées ensuite les populations [10]. Ces préoccupations existent également en médecine vétérinaire [11]. Les animaux d'élevage sont particulièrement concernés par les affections et les épidémies d'origine virale (dans un contexte de vaccination parcimonieuse et d'efficacité discutée $[12,13]$ ) et par de nombreuses surinfections 
bactériennes imposant un recours fréquent et massif aux antibiotiques, favorable au développement d'antibiorésistances [14].

Cette lutte contre les infections virales et le développement d'antibiorésistances en médecine humaine et vétérinaire constitue un enjeu d'autant plus important que la santé des animaux et celle des hommes sont indissociables (transmissions mutuelles, hybridation entre souches, etc.) et que l'arsenal thérapeutique est commun et limité [15]. Développer des approches complémentaires efficaces est donc nécessaire [16-18].

L'utilisation des plantes ou de leurs extraits constitue une option intéressante pour prévenir et traiter les infections virales chez l'Homme et l'animal, car les plantes ont développé des combinaisons de composés bioactifs qui les protègent des micro-organismes $[19,20]$. L'activité antivirale de composés présents dans des extraits de plantes - essentiellement des polyphénols et des tanins - a été montrée sur les virus impliqués dans les infections respiratoires liées au virus influenza A [18,21-28]. L'effet antiviral d'un extrait de cônes de cyprès a par ailleurs été rapporté sur le virus herpès simplex HSV-1 appartenant à la même famille que l'herpèsvirus bovin de type 1 responsable de la rhinotrachéite infectieuse bovine [29].

L'objectif de cette étude était d'identifier les principaux composés chimiques d'un extrait de cônes frais de cyprès et de tester, selon les normes européennes (NF EN 14476+A1 octobre 2015 [30] et NF EN 14675 mai 2015 [31]), son activité virucide sur quatre virus à tropisme respiratoire chez l'Homme, dont trois virus pour lesquels aucun extrait de plantes n'avait été testé auparavant, ainsi que, pour la première fois, sur des virus bovins, deux à tropisme respiratoire et un à tropisme intestinal. Les quatre virus à tropisme respiratoire chez l'Homme étaient le coronavirus, le virus influenza A-H1N1, le virus parainfluenza de type 3 et le rhinovirus. Ces quatre virus font partie des plus couramment impliqués dans les syndromes respiratoires [32]. Les trois virus bovins étaient l'herpèsvirus bovin de type 1 et le virus respiratoire syncytial bovin pour lesquels un manque d'efficacité vaccinale a été rapporté [12] et le rotavirus bovin dont l'implication dans les entérites et diarrhées néonatales est bien connue [13].

\section{Matériel et méthodes}

\section{Extrait de Cupressus sempervirens L.}

L'extrait hydroéthanolique de cônes frais de cyprès récoltés en France en 2015 a été obtenu selon le procédé Phytostandard ${ }^{\circledR}$. Cet extrait liquide est commercialisé sous le nom d'EPS Cyprès (PiLeJe Laboratoire, France).

\section{Analyse HPTLC de l'extrait hydroéthanolique de Cupressus sempervirens $\mathrm{L}$.}

L'extrait hydroéthanolique de Cupressus sempervirens L. (1 $\mathrm{ml})$ a été dilué dans $3 \mathrm{ml}$ d'un mélange eau/éthanol $(40 / 60 \mathrm{v} / \mathrm{v})$. Cette solution a été centrifugée cinq minutes à $4400 \mathrm{rpm}$. Le surnageant a été analysé par HPTLC.

L'analyse a été faite sur des plaques en verre de gel de silice 60 F254 HPTLC 200,0 × 100,0 mm (Merck, Germany). Les échantillons ont été déposés en bande de $8,0 \mathrm{~mm}$ de largeur avec le déposeur automatique d'échantillons Camag (ATS4, Muttenz, Suisse). Les bandes ont été déposées à $6,0 \mathrm{~mm}$ du bas de la plaque et à $15,0 \mathrm{~mm}$ des bords droit et gauche de la plaque. L'espace entre les bandes était de 7,3 $\mathrm{mm}$. La distance de migration était de $50,0 \mathrm{~mm}$ à partir du bord inférieur de la plaque dans une cuve de développement horizontale Camag. La révélation des plaques a été réalisée en utilisant un système d'immersion et une plaque chauffante Camag. Les images ont été capturées avec le visualiseur Camag et le logiciel WinCATS. Les conditions spécifiques pour chaque type de composé sont présentées dans le tableau 1.

\section{Analyse LC/MS de l'extrait hydroéthanolique de Cupressus sempervirens $\mathrm{L}$.}

Les analyses chromatographiques (LC/MS et $\mathrm{MS}^{2}$ ) ont été réalisées avec un système Ultimate 3000 RSLC UHPLC (Thermo Fisher Scientific Inc., MA, États-Unis) couplé à une pompe binaire (U3000 HPG-3400RS) et un détecteur à barrette de diodes. Les composés ont été séparés sur une colonne C18 Uptisphere Strategy $(25 \times 4,6 \mathrm{~mm} ; 5 \mu \mathrm{m}$; Interchim, France) contrôlée à $40^{\circ} \mathrm{C}$. La phase mobile était un mélange d'acide formique à $0,1 \%(\mathrm{v} / \mathrm{v})$ dans l'eau (phase $\mathrm{A})$ et d'acide formique à $0,1 \%(\mathrm{v} / \mathrm{v})$ dans l'acétonitrile (phase B). Le gradient pour la phase A était : $100 \%$ (0 minute), $80 \%$ (10 minutes), $73 \%$ (35 minutes), $0 \%$ (40-49 minutes), $100 \%$ (50-60 minutes). Le débit était de $0,8 \mathrm{ml} / \mathrm{min}$, et $5 \mu l$ ont été injectés. Le système UHPLC était connecté à un spectromètre de masse Q-Exactive Orbitrap (Thermo Fisher Scientific Inc., MA, États-Unis), opérant en ionisation électrospray dans un mode négatif. Les conditions opératoires de la source étaient : $3 \mathrm{kV}$ de tension de spray pour le mode négatif ; température du capillaire à $320^{\circ} \mathrm{C}$; température du gaz auxiliaire à $475^{\circ} \mathrm{C}$; gaz (azote) d'enveloppe, de balayage et auxiliaire à un débit de 60,18 et 4 unités arbitraires, respectivement ; et une cellule de collision avec une énergie comprise entre 20 et $50 \mathrm{eV}$.

Les données du spectre ont été obtenues avec une résolution de 35000 , et les données $\mathrm{MS}^{2}$ avec une résolution de 17 500. Les résultats ont été exploités avec le logiciel Xcalibur (Thermo Fisher Scientific Inc., MA, États-Unis). 
Tableau 1 Conditions chromatographiques pour l'analyse HPTLC des acides aminés, glucides, flavonoïdes, acides phénoliques et dérivés catéchiques

\begin{tabular}{|c|c|c|c|c|}
\hline & Dépôt $(\mu \mathrm{l})$ & Phase mobile & Révélation & Visualisation \\
\hline Acides aminés & 1 & $\begin{array}{l}\text { Butanol/acétone/acide } \\
\text { acétique/eau }(7 / 7 / 2 / 4) \\
\text { avec } 100 \mathrm{mg} \\
\text { de ninhydrine dissous }\end{array}$ & $\begin{array}{l}\text { Séchage pendant } 10 \mathrm{~min} \text { sous hotte puis chauffage } \\
\text { pendant } 3 \mathrm{~min} \text { à } 110^{\circ} \mathrm{C} \text { sur plaque chauffante }\end{array}$ & $\begin{array}{l}\text { Lumière } \\
\text { blanche }\end{array}$ \\
\hline Glucides & 1 & $\begin{array}{l}\text { Butanol/eau/acide } \\
\text { acétique }(10 / 3 / 1)\end{array}$ & $\begin{array}{l}\text { Séchage pendant } 10 \text { min sous hotte, immersion } \\
\text { dans la diphénylamine-aniline, puis chauffage pendant } \\
5 \text { min à } 120{ }^{\circ} \mathrm{C} \text { sur plaque chauffante }\end{array}$ & $\begin{array}{l}\text { Lumière } \\
\text { blanche }\end{array}$ \\
\hline $\begin{array}{l}\text { Flavo- } \\
\text { noïdes et acides } \\
\text { phénoliques }\end{array}$ & 1 & $\begin{array}{l}\text { Acétate d'éthyle/eau/ } \\
\text { acide acétique/acide } \\
\text { formique }(100 / 26 / 11 / 11)\end{array}$ & $\begin{array}{l}\text { Séchage pendant } 10 \text { min sous hotte, chauffage pendant } \\
3 \text { min à } 110{ }^{\circ} \mathrm{C} \text { sur plaque chauffante, puis immersion } \\
\text { de la plaque encore chaude dans le NP (natural product) } \\
\text { puis le PEG (polyéthylène glycol) }\end{array}$ & $366 \mathrm{~nm}$ \\
\hline $\begin{array}{l}\text { Dérivés } \\
\text { catéchiques }\end{array}$ & 0,4 & $\begin{array}{l}\text { Toluène/acétone/acide } \\
\text { formique }(9 / 9 / 2)\end{array}$ & $\begin{array}{l}\text { Séchage pendant } 10 \text { min sous hotte, chauffage pendant } \\
2 \text { min à } 100{ }^{\circ} \mathrm{C} \text { sur plaque chauffante, puis immersion } \\
\text { de la plaque encore chaude dans le Fast Blue Salt B }\end{array}$ & $\begin{array}{l}\text { Lumière } \\
\text { blanche }\end{array}$ \\
\hline
\end{tabular}

Les composés présents dans l'extrait ont été identifiés selon leur temps de rétention, leur spectre de masse et par comparaison avec des standards lorsqu'ils étaient à disposition ou avec des données de la littérature.

\section{Quantification des tanins}

Les tanins ont été quantifiés par la méthode de Bate-Smith et Rasper [33].

\section{Activité virucide}

Pour les quatre virus infectant l'Homme (coronavirus, virus influenza A-H1N1, virus parainfluenza de type 3 et rhinovirus), l'activité virucide a été déterminée selon les indications de la norme NF EN 14476+A1 (octobre 2015) « Antiseptiques et désinfectants chimiques. Essai quantitatif de suspension pour l'évaluation de l'activité virucide des antiseptiques et des désinfectants chimiques utilisés dans le domaine médical. Méthode d'essai et prescriptions (phase 2, étape 1) » [30].

Pour les trois virus bovins (herpèsvirus bovin de type 1, virus respiratoire syncytial bovin et rotavirus bovin), l'activité virucide a été déterminée selon les indications de la norme NF EN 14675 (mai 2015) « Antiseptiques et désinfectants chimiques. Essai quantitatif de suspension pour l'évaluation de l'activité virucide des antiseptiques et des désinfectants chimiques utilisés dans le domaine vétérinaire. Méthodes d'essai et prescriptions (phase 2, étape 1) » [31].

Les souches virales ont été obtenues auprès de l'ATCC (American Type Culture Collection, Molsheim, France) et amplifiées sur des lignées cellulaires spécifiques (Tableau 2), en milieu minimum essentiel d'Eagle (EMEM ; Sigma
Aldrich) ou en EMEM modifié par Dulbecco/Vogt (DMEM ; Sigma Aldrich).

Les tests ont été réalisés en conditions de propreté (en présence de $0,3 \mathrm{~g} / 1 \mathrm{~d}$ 'albumine de sérum bovin) pour les quatre virus infectant l'Homme et en conditions de saleté de faible niveau (en présence de $3 \mathrm{~g} / \mathrm{l}$ d'albumine de sérum bovin) pour les trois virus bovins et pour des solutions d'extrait de cyprès à $80,40,20$ et $1 \% \mathrm{v} / \mathrm{v}$ préparées dans l'eau dure pour les quatre virus infectant l'Homme et dans l'eau pour préparation injectable (Cooper) pour les trois virus bovins. Le contact avec les différentes solutions d'extrait de cyprès a été maintenu pendant 60 minutes \pm 10 secondes à $37 \pm 1{ }^{\circ} \mathrm{C}$. L'arrêt de l'activité de l'extrait de cyprès a été obtenu par tamisage moléculaire des dilutions 1/10 sur filtre Sephadex ${ }^{\mathrm{TM}}$ LH-20 (Dutscher).

Le titrage viral a été effectué en microplaques par la méthode des cellules en suspension. L'effet cytopathique a été déterminé après quatre jours d'incubation à $36 \pm 1{ }^{\circ} \mathrm{C}$. Des titrages comparatifs ont été réalisés sur les cellules en absence et en présence subcytotoxique d'extrait de cyprès afin de vérifier que le comportement du virus vis-à-vis des cellules réceptrices n'était pas modifié.

Le nombre d'unités infectieuses a été estimé par la méthode de Spearman-Karber décrite en annexe des normes de référence en calculant le logarithme négatif du point limite $50 \%\left(\operatorname{lgDICT}{ }_{50}\right)$ par la formule suivante :

$\operatorname{lgDICT} T_{50}=$ logarithme négatif de la plus haute concentration de virus utilisée - [(somme de \% affecté à chaque dilution $/ 100-0,5) \times(\lg$ de dilution $)]$

La réduction logarithmique est la différence entre le titre de l'infectivité sans exposition au produit et le titre de l'infectivité obtenu après exposition au produit pour le temps de contact spécifique choisi. Le produit testé était dit virucide si 


\begin{tabular}{|c|c|c|c|c|}
\hline Virus & Enveloppe & $\begin{array}{l}\text { Souche } \\
\text { ATCC }\end{array}$ & Cellule réceptrice & Milieu \\
\hline \multicolumn{5}{|l|}{ Virus infectant l'homme } \\
\hline Coronavirus & + & VR-740 & Vero (ATCC CCL-81) & EMEM \\
\hline Virus influenza A-H1N1 & + & VR-1520 & MDCK (ATCC CCL-34) & DMEM \\
\hline Virus parainfluenza de type 3 & + & VR-93 & Vero (ATCC CCL-81) & DMEM \\
\hline Rhinovirus & - & VR-484 & HeLa (ATCC CCL-2) & EMEM \\
\hline \multicolumn{5}{|l|}{ Virus bovin } \\
\hline Herpèsvirus bovin de type 1 & + & VR-864 & BTcell (ATCC CRL-1390) & DMEM \\
\hline Virus respiratoire syncytial bovin & + & VR-1339 & BTcell (ATCC CRL-1390) & DMEM \\
\hline Rotavirus bovin & - & VR-1290 & MA 104 (ECACC 85102918) & EMEM \\
\hline
\end{tabular}

cette réduction logarithmique était supérieure ou égale à $4 \log$ de réduction.

Un essai en présence de formaldéhyde a été réalisé pour contrôler l'inactivation des virus d'essai, sauf pour le virus influenza A-H1N1 qui a été mis en présence d'éthanol $40 \%$.

\section{Résultats}

\section{Composés identifiés dans l'extrait hydroéthanolique de Cupressus sempervirens L.}

L'analyse HPTLC de l'extrait hydroéthanolique de Cupressus sempervirens L. a montré la présence d'acides aminés, de glucides, de flavonoïdes et de dérivés catéchiques (Fig. 1). L'analyse des dérivés catéchiques a montré que l'extrait contient de la catéchine (pistes 3 et 4, Fig. 1).

L'analyse UHPLC-MS a confirmé la présence de catéchine (signal 13 en Fig. 2 ; Tableau 3 ) et montré celle d'épicatéchine (signal 16). De nombreuses proanthocyanidines avec deux (signaux 9, 14, 18), trois (signaux 3, 10, 12, 15) ou quatre (signaux $5,7,8,11,15,17$ ) unités de catéchine ou d'épicatéchine ont aussi été identifiées. La structure de la catéchine, de l'épicatéchine et de la proanthocyanidine B1 est présentée en figure 3.

La quantification des tanins a montré que l'extrait de cyprès en contenait $7,52 \%$.

\section{Activité virucide}

Les résultats montrent que l'extrait de cyprès à $80 \% \mathrm{v} / \mathrm{v}$ a eu un effet virucide sur les sept virus (Tableau 4). L'extrait de cyprès à $40 \% \mathrm{v} / \mathrm{v}$ a eu aussi un effet virucide sur quatre d'entre eux : sur le coronavirus et le virus parainfluenza de

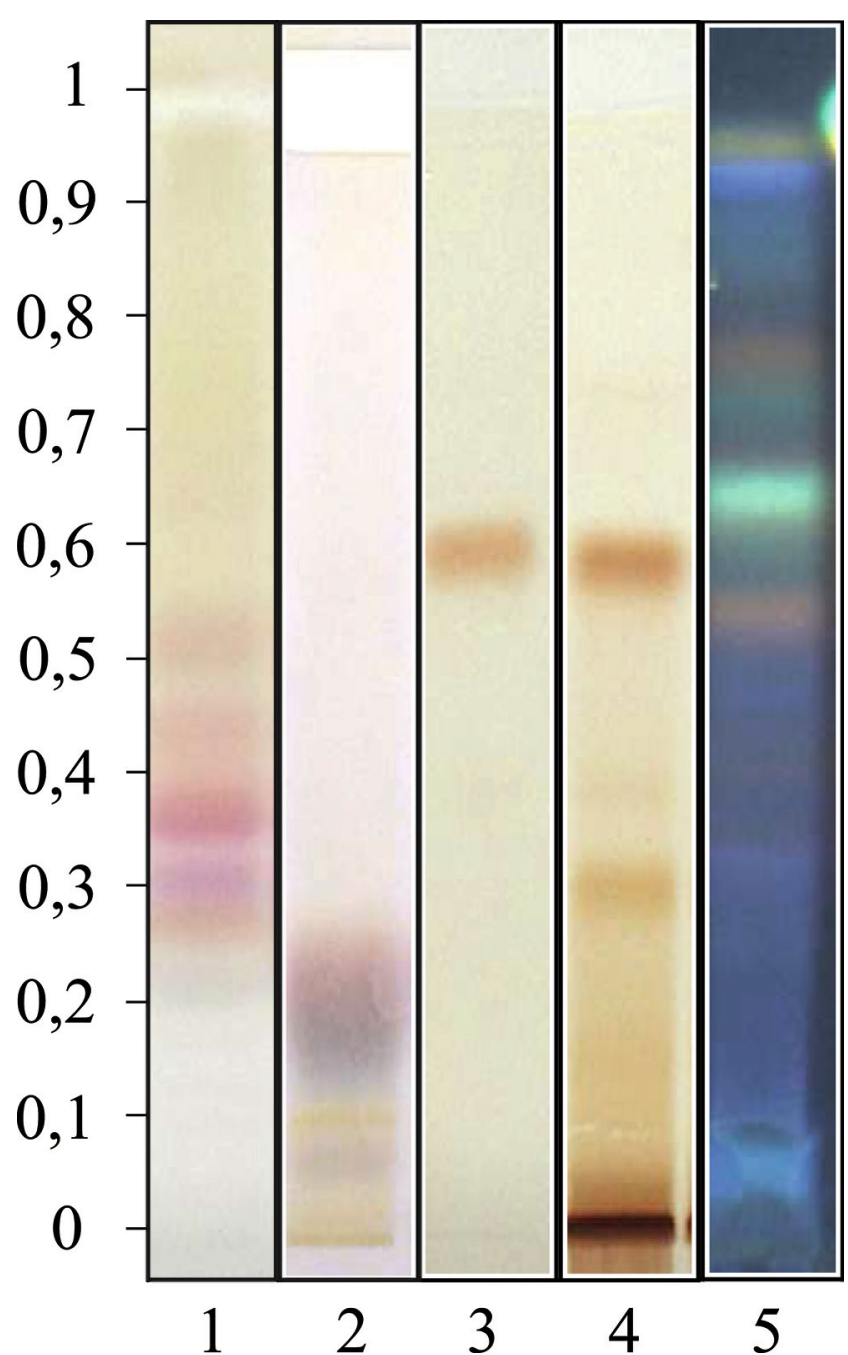

Fig. 1 Analyse HPTLC. Piste 1 : acides aminés ; piste 2 : glucides ; piste 3 : standard catéchine ; piste 4 : dérivés catéchiques ; piste 5 : flavonoïdes 


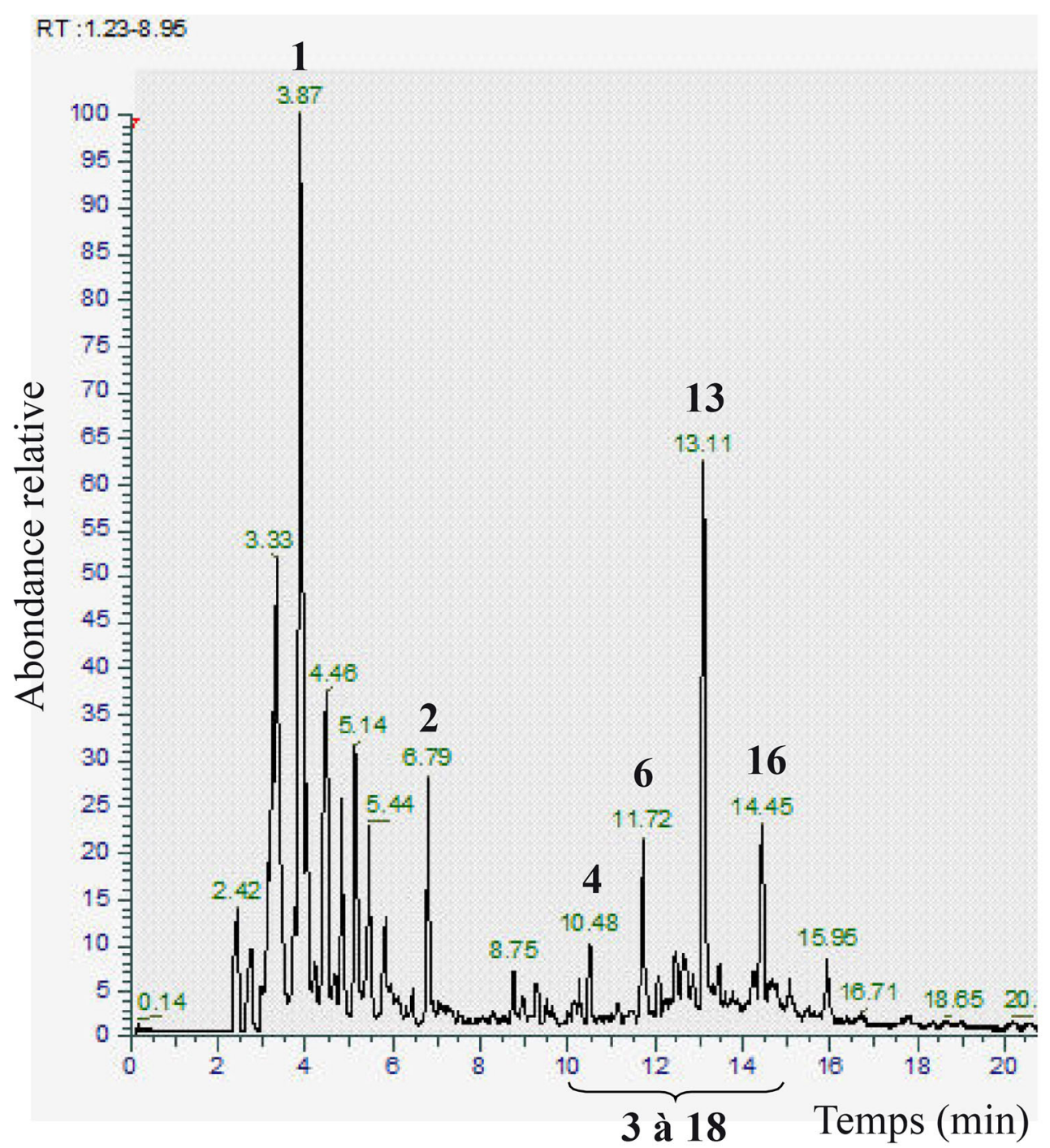

Fig. 2 Chromatogramme LC-MS de l'extrait hydroéthanolique de Cupressus sempervirens L. en mode négatif

type 3 pour les virus infectant l'Homme et sur le virus respiratoire syncytial bovin et le rotavirus bovin.

\section{Discussion}

L'extrait de cyprès testé a eu un effet virucide sur tous les virus d'essai quel que soit leur type, nu ou enveloppé. L'effet virucide a été obtenu pour les sept virus lorsque la concentration de l'extrait de cyprès était de $80 \% \mathrm{v} / \mathrm{v}$, et sur quatre d'entre eux lorsque la concentration était de $40 \% \mathrm{v} / \mathrm{v}$ (coronavirus et virus parainfluenza de type 3 pour les virus humains et virus respiratoire syncytial et rotavirus bovins). L'analyse phytochimique a montré que l'extrait de cyprès contient de la catéchine, de l'épicatéchine et des tanins de type proanthocyanidine, composés d'unités de catéchine ou d'épicatéchine. La présence d'acides aminés, de glucides et de flavonoïdes a également été détectée.
Les composés actifs des plantes peuvent avoir une activité virucide en impactant différentes étapes de l'infection des cellules. Brièvement, les étapes de l'infection virale sont les suivantes :

- le virus s'attache à la cellule (une protéine virale se lie à un récepteur de la membrane cellulaire) ;

- il pénètre dans la cellule par des mécanismes différents selon le type de virus ;

- le virus libère son matériel génétique (décapsidation) dans le cytoplasme ou dans le noyau de la cellule infectée ;

- sa réplication ;

- l'assemblage, la maturation des nouvelles particules virales et l'encapsulation du génome ont lieu dans la cellule infectée ;

- les virus sont libérés par éclatement de la cellule pour les virus nus et par bourgeonnement membranaire pour les virus enveloppés. 


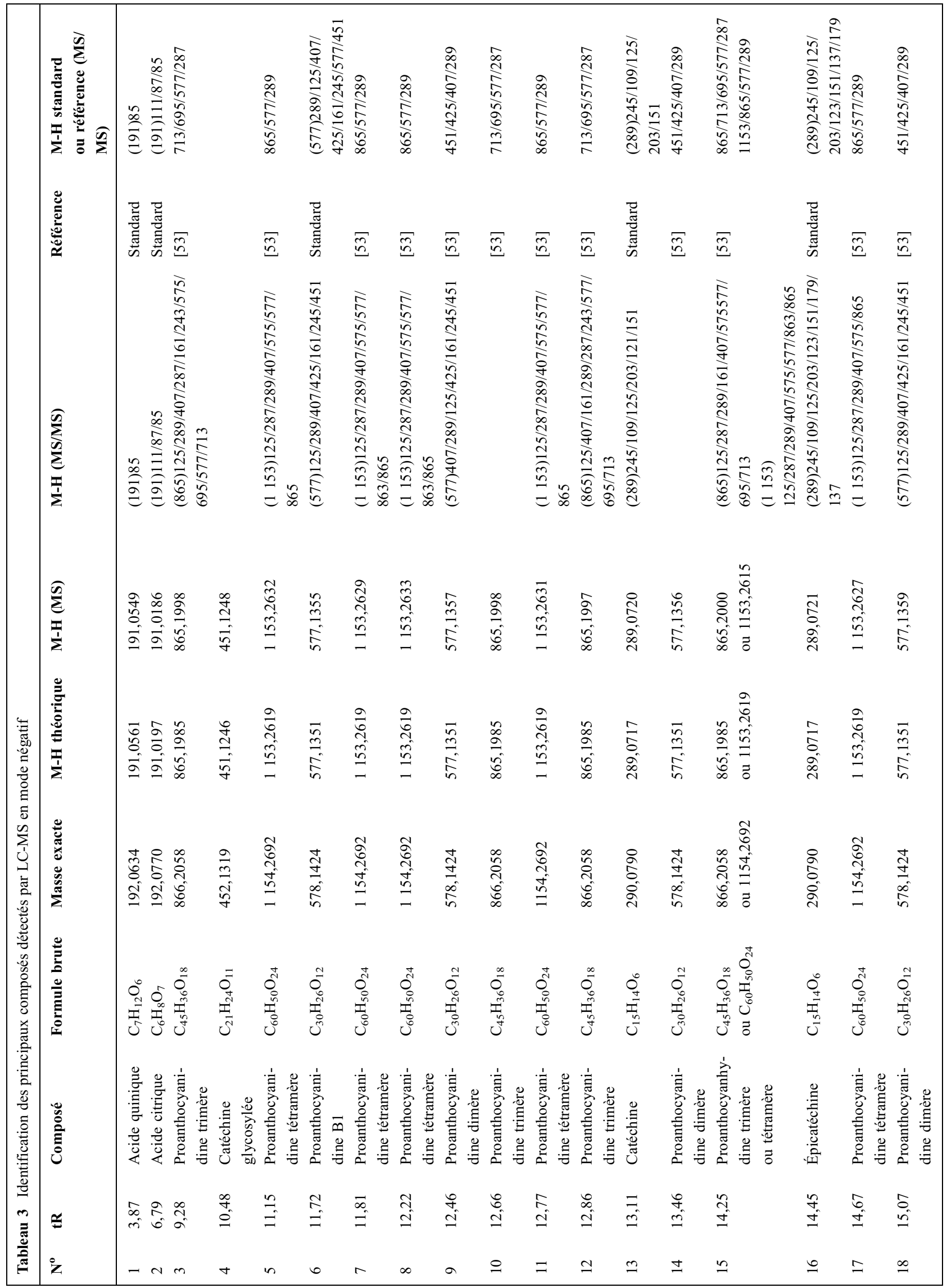




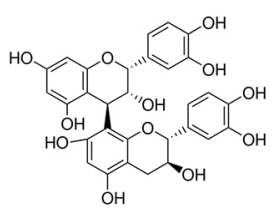

Proanthocyanidine B1

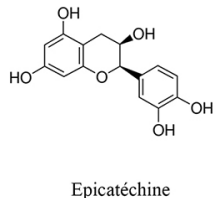

Epicatéchine

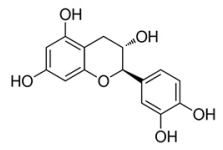

Catéchine
Fig. 3 Structure de la proanthocyanidine B1, la catéchine et l'épicatéchine

Tableau 4 Réduction logarithmique du titre viral DICT50 pour les différentes concentrations d'extrait de cyprès

\begin{tabular}{|c|c|c|c|c|}
\hline \multirow[t]{2}{*}{ Virus } & \multicolumn{4}{|c|}{ Extrait de cyprès (v/v) } \\
\hline & $80 \%$ & $40 \%$ & $20 \%$ & $1 \%$ \\
\hline \multicolumn{5}{|l|}{ Virus infectant l'Homme } \\
\hline Coronavirus & $4,3^{\mathrm{a}}$ & $4,2^{\mathrm{a}}$ & 1,5 & 0,1 \\
\hline Virus influenza A-H1N1 & $4,3^{\mathrm{a}}$ & 3,5 & 1,9 & 0 \\
\hline $\begin{array}{l}\text { Virus parainfluenza } \\
\text { de type } 3\end{array}$ & $>5^{\mathrm{a}}$ & $4,3^{\mathrm{a}}$ & 2,8 & 0,6 \\
\hline Rhinovirus & $4,3^{\mathrm{a}}$ & 3,4 & 2,1 & 0,4 \\
\hline \multicolumn{5}{|l|}{ Virus bovin } \\
\hline Herpèsvirus bovin de type 1 & $\geq 4,2^{\mathrm{a}}$ & 3,4 & 2,5 & 1,0 \\
\hline $\begin{array}{l}\text { Virus respiratoire syncytial } \\
\text { bovin }\end{array}$ & $\geq 4,4^{\mathrm{a}}$ & $4,2^{\mathrm{a}}$ & 2,3 & 1,3 \\
\hline Rotavirus bovin & $4,8^{\mathrm{a}}$ & $4,5^{\mathrm{a}}$ & 1,6 & 0,4 \\
\hline
\end{tabular}

Mélangés à une solution virale, les tanins sont connus pour former des complexes plus ou moins réversibles avec les protéines de surface des virus, protéines de la capside pour un virus nu et protéines d'enveloppe pour un virus enveloppé. L'encombrement stérique et les changements conformationnels engendrés induisent ainsi la perte du pouvoir infectieux des virus [34]. Le virus influenza A-H1N1 est un virus dont l'enveloppe comporte des spicules formés par l'hémagglutinine et la neuraminidase. C'est l'hémagglutinine qui permet l'attachement à la membrane cellulaire et la fusion avec la membrane de l'endosome libérant la capside dans le cytoplasme. Des études ont montré que des tanins issus de différentes plantes inhibent l'attachement et la pénétration du virus influenza A-H1N1 par agrégation de cette protéine [23,35-37]. Les tanins présents dans l'extrait de cyprès pourraient donc avoir produit la perte du pouvoir infectieux du virus influenza A-H1N1 de la même manière, ainsi que celle des autres virus enveloppés qui comportent aussi des protéines d'enveloppe impliquées dans l'attachement et la pénétration. Par exemple, l'enveloppe de l'herpèsvirus bovin de type 1 comporte des glycoprotéines impliquées dans l'attachement et la pénétration du virus, pour lesquelles l'affinité des proanthocyanidines a été rapportée
[38,39]. Il est intéressant de noter que l'effet antiviral des proanthocyanidines d'un extrait de cônes de Cupressus sempervirens L. a été rapporté pour d'autres virus enveloppés (le virus de l'immunodéficience humaine et le virus T-lymphotropique humain III B) et que cet effet antiviral était lié en l'occurrence à l'inhibition de l'attachement par inactivation de glycoprotéines d'enveloppe [16]. Par ailleurs, pour les virus nus dont la capside comporte des protéines de liaison et des protéines structurelles, la perte de leur pouvoir infectieux en présence de tanins peut être liée à la fois à l'inhibition de l'attachement et à la déstabilisation de la structure de la capside [40].

Au-delà des conséquences des interactions entre les tanins et les protéines de surface des virus sur l'attachement, la pénétration, la fusion ou l'intégrité de la capside, d'autres mécanismes pourraient être impliqués dans la perte du pouvoir infectieux des virus après contact avec l'extrait de cyprès. Par exemple, une interaction avec les protéoglycanes présents à la surface de nombreuses cellules pourrait inhiber l'attachement [41,42]. L'inhibition d'enzymes peut bloquer l'expression de corécepteurs cellulaires nécessaires à la pénétration du virus (cela a été rapporté pour le virus de l'immunodéficience humaine de type 1 avec des oligomères proanthocyanidoliques d'extraits de pépins de raisin [43]) ou avoir un impact sur différentes activités indispensables à la réplication virale, à l'assemblage et à la libération des virus nouvellement formés. Il a été rapporté notamment que l'inactivation de la neuraminidase avec des extraits de thé $[23,35]$ ainsi qu'avec de la catéchine et de l'acide gallique issus d'acajou de Chine [44] bloquait la libération du virus influenza A-H1N1 des cellules infectées.

Il est important de souligner que l'extrait de cyprès testé dans la présente étude contient en plus des tanins, dont les effets sur les virus ont été largement documentés, d'autres composés dont la contribution à l'effet virucide ne peut être exclue.

Chez l'animal et chez l'Homme, des effets bénéfiques de différents extraits de plantes ont été rapportés lors d'une infection par le virus influenza [27,35,37,45-50]. Il serait donc intéressant d'évaluer aussi les effets de l'extrait de cyprès, seul et en association aux traitements conventionnels, chez l'Homme, ainsi qu'en utilisation prophylactique et thérapeutique complémentaire chez les bovins. Des effets inhibiteurs combinés contribuent en effet à limiter l'émergence de virus résistants (voir, par exemple, le bénéfice lié à l'inhibition combinée de la neuraminidase et de protéases dans le traitement de l'infection virale influenza [51]), et des bénéfices thérapeutiques permettraient de maîtriser davantage les risques, les complications des infections virales et le recours aux antibiothérapies. Il a notamment été suggéré d'associer des composés polyphénoliques naturels en traitement adjuvant aux antiviraux conventionnels dans le traitement de l'infection virale influenza [52]. 


\section{Conclusion}

La présente étude a montré un effet virucide de l'extrait hydroéthanolique de Cupressus sempervirens L. sur quatre virus à tropisme respiratoire chez l'Homme, dont des virus pour lesquels aucun extrait de plante n'avait été testé auparavant, et pour la première fois sur des virus bovins. Les virus ont perdu leur pouvoir infectieux après contact in vitro avec l'extrait de cyprès pendant 60 minutes \pm 10 secondes à $37 \pm 1{ }^{\circ} \mathrm{C}$. L'analyse phytochimique de l'extrait a révélé qu'il contient de la catéchine, de l'épicatéchine, des tanins de type proanthocyanidines et également des acides aminés, des glucides et des flavonoïdes. L'effet virucide observé in vitro devra être confirmé par des études d'efficacité chez l'Homme et le bovin. Chez l'Homme, par exemple, l'extrait de cônes de cyprès administré par voie orale pourrait être testé en traitement prophylactique de la contamination virale des personnels soignants et des proches des patients symptomatiques, et chez les patients eux-mêmes en association aux antiviraux conventionnels. Ces études pourraient faire de l'extrait de cyprès une solution de santé intéressante pour des conduites prophylactiques et thérapeutiques complémentaires aux traitements usuels, avec une diminution des conditions de recours aux antibiothérapies.

Remerciements Nous remercions Jean-Philippe Petit (rédacteur indépendant) et Claude Blondeau (PiLeJe Laboratoire) pour leur assistance rédactionnelle et éditoriale

\section{Liens d'intérêts :}

I. Guinobert, V. Bardot et C. Faivre, respectivement Chef de Projets Recherche, Responsable Développement Ingrédients et Responsable Wamine au sein du Groupe PiLeJe, L. Berthomier et I. Ripoche (Sigma), ont réalisé les analyses phytochimiques, L. Haddioui et H. Belkhelfa (Fonderephar) ont réalisé les études de l'activité virucide pour le Groupe PiLeJe.

\section{Références}

1. Bergeron A (2016) Infections virales des voies respiratoires : stratégie thérapeutique. Le Webzine de la HAS. Magazine des bonnes pratiques. Pneumologie. https://www.has-sante.fr/portail/ jcms/c_2042689/fr/infections-virales-des-voies-respiratoires-strategie-therapeutique (Dernier accès le 20 juin 2018)

2. Field AK, Biron KK (1994) The end of innocence. Revisited: resistance of herpesviruses to antiviral drugs. Clin Microbiol Rev 7:1-13

3. Baz M, Abed Y, Papenburg J, et al (2009) Emergence of oseltamivir-resistant pandemic $\mathrm{H} 1 \mathrm{~N} 1$ virus during prophylaxis. N Engl J Med 361:2296-7

4. Gaur AH, Bagga B, Barman S, et al (2010) Intravenous zanamivir for oseltamivir-resistant 2009 H1N1 influenza. N Engl J Med 362:88-9
5. Van der Vries E, Stelma FF, Boucher CAB (2010) Emergence of a multidrugresistant pandemic influenza $\mathrm{A}(\mathrm{H} 1 \mathrm{~N} 1)$ virus. N Engl J Med 363:1381-2

6. Hurt AC, Hardie K, Wilson NJ, et al (2011) Community transmission of oseltamivir-resistant A(H1N1)pdm09 influenza. N Engl J Med 365:2541-2

7. Lackenby A, Moran Gilad J, Pebody R, et al (2011) Continued emergence and changing epidemiology of oseltamivir-resistant influenza A(H1N1)2009 virus. United Kingdom, winter 2010/11. Eurosurveillance 16:1-6. https://www.eurosurveillance.org/content/ 10.2807/ese.16.05.19784-en (Dernier accès le 20 juin 2018)

8. Boivin G (2013) Detection and management of antiviral resistance for influenza viruses. Influenza Other Respir Viruses 7:18-23

9. Grimprel E, Cohen R (2010) Relation entre la grippe et les infections bactériennes. MT Pediatr 13:316-21

10. Le Fur PH, Serment C (1995) Bronchopneumopathies aiguës et antibiothérapie en 1992. Aspects socioéconomiques. Bull CREDES 1062:1-35

11. Ministère de l'Agriculture et de l'Alimentation (2017) ECOANTIBIO2 : Plan national de réduction des risques d'antibiorésistance en médecine vétérinaire 2017-2021. http://agriculture. gouv.fr/le-plan-ecoantibio-2-2017-2021. http://agriculture.gouv.fr/ le-plan-ecoantibio-2-2017-2021 (Dernier accès le 20 juin 2018)

12. Centre belge d'information pharmacothérapeutique (2003) La vaccination contre les viroses respiratoires du bétail est-elle efficace ? Folia Veterinaria 15 juin 2003. https://www.vetcompendium.be/sites/default/files/03fvf2a.pdf (Dernier accès le 20 juin 2018)

13. Centre belge d'information pharmacothérapeutique (2004) Diarrhées néonatales du veau et choix raisonné de l'antibiothérapie. Folia Veterinaria 15 juin 2004. https://www.vetcompendium.be/ sites/default/files/04fvf2d.pdf (Dernier accès le 20 juin 2018)

14. Larsen LE (2000) Bovine respiratory syncytial virus (BRSV): a review. Acta Vet Scand 41:1-24

15. Ministère de l'Agriculture et de l'Alimentation (2015) Lutte contre l'antibiorésistance : une seule santé, une seule planète. http://agriculture.gouv.fr/ecoantibio-2017-une-seule-sante-uneseule-planete (Dernier accès le 20 juin 2018)

16. Amouroux P, Jean D, Lamaison JL (1998) Antiviral activity in vitro of Cupressus sempervirens on two human retroviruses HIV and HTLV. Phytother Res 12:367-8

17. Perera C, Efferth T (2012) Antiviral medicinal herbs and phytochemicals. J Pharmacogn 3:45-8

18. Theisen LL, Erdelmeier CAJ, Spoden GA, et al (2014) Tannins from Hamamelis virginiana bark extract: characterization and improvement of the antiviral efficacy against influenza A virus and human papillomavirus. PLoS One 9:e88062

19. Chattopadhyay D, Naik TN (2007) Antivirals of ethnomedicinal origin: structure activity relantionship and scope. Mini Rev Med Chem 7:275-301

20. Wink M (2008) Evolutionary advantage and molecular modes of action of multi-component mixtures used in phytomedicine. Curr Drug Metab 10:996-1009

21. Carson RS, Frisch AW (1953) The inactivation of influenza viruses by tannic acid and related compounds. J Bacteriol 66:572-5

22. Nakayama M, Suzuki K, Toda M, et al (1993) Inhibition of the infectivity of influenza virus by tea polyphenols. Antiviral Res 21:289-99

23. Song JM, Lee KH, Seong BL (2005) Antiviral effect of catechins in green tea on influenza virus. Antivir Res 68:66-74

24. Choi HJ, Song JH, Park KS, Kwon DH (2009) Inhibitory effects of quercetin 3-rhamnoside on influenza A virus replication. Eur J Pharm Sci 37:329-33

25. Wirotesangthong M, Nagai T, Yamada H, et al (2009) Effects of Clinacanthus siamensis leaf extract on influenza virus infection. Microbiol Immunol 53: 66-74 
26. Liu G, Xiong S, Xiang YF, et al (2011) Antiviral activity and possible mechanisms of action of pentagalloylglucose (PGG) against influenza A virus. Arch Virol 156:1359-69

27. Theisen LL, Muller CP (2012) EPsH 7630 (UmckaloaboH), an extract from Pelargonium sidoides roots, exerts anti-influenza virus activity in vitro and in vivo. Antiviral Res 94:147-56

28. Enkhtaivan G, Maria John KM, et al (2015) Anti-influenza (H1N1) potential of leaf and stem bark extracts of selected medicinal plants of South India. Saudi J Biol Sci 22:532-8

29. Emami SA, Tayarani-Najaran Z, Ghannad MS, et al (2009) Antiviral activity of obtained extracts from different parts of Cupressus sempervirens against herpes simplex virus type 1. Iran J Basic Med Sci 12:133-9

30. Afnor (2015) NF EN 14476+A1 octobre 2015. Antiseptiques et désinfectants chimiques. Essai quantitatif de suspension pour l'évaluation de l'activité virucide des antiseptiques et des désinfectants chimiques utilisés dans le domaine médical. Méthode d'essai et prescriptions (phase 2, étape 1)

31. Afnor (2015) NF EN 14675 mai 2015. Antiseptiques et désinfectants chimiques. Essai quantitatif de suspension pour l'évaluation de l'activité virucide des antiseptiques et des désinfectants chimiques utilisés dans le domaine vétérinaire. Méthodes d'essai et prescriptions (phase 2, étape 1)

32. Pringle CR (2018) Revue générale des infections virales respiratoires. Le manuel MSD pour les professionnels de la santé, Merck and Co., Inc., Kenilworth, NJ, États-Unis. https://www. msdmanuals.com/fr/professional/maladies-infectieuses/virus-respiratoires/revue-g\%C3\%A9n\%C3\%A9rale-des-infections-viralesrespiratoires (Dernier accès le 20 juin 2018)

33. Bate-Smith EC, Rasper V (1969) Tannins of grains sorghum: luteoforol (leucoluteolinidin), 1',4,4'5,7-pentahydroxyflavan. J Food Sci 34:203-9

34. Chambon M, Bailly JL, Peigue-Lafeuille H (1999) Antiseptiques, désinfectants chimiques et virus en secteur médical. Virologie 3:367-78

35. Noguchi A, Hamauzu Y, Yasui H (2008) Inhibitory effects of Goishi tea against influenza virus infection. Food Sci Technol Res 14:277-84

36. Yang Z, Wang Y, Zhong S, et al (2012) In vitro inhibition of influenza virus infection by a crude extract from Isatis indigotica root resulting in the prevention of viral attachment. Mol Med Rep 5:793-9

37. Ho JY, Chang HW, Lin CF, et al (2014) Characterization of the anti-influenza activity of the Chinese herbal plant Paeonia lactiflora. Viruses 6:1861-75

38. Barber KA, Daugherty HC, Ander SE, et al (2017) Protein composition of the bovine herpesvirus 1.1 virion. Vet Sci 4:1-16
39. Gescher K, Kühn J, Hafezi W, et al (2011) Inhibition of viral adsorption and penetration by an aqueous extract from Rhododendron ferrugineum $\mathrm{L}$. as antiviral principle against herpes simplex virus type-1. Fitoterapia 82:408-13

40. Cordey S, Schibler M, Tapparel C, Kaiser L (2008) Rhinovirus : diversité clinique et génomique. Virologie 12:361-73

41. Bernfield M, Götte M, Park PW, et al (1999) Functions of cell surface heparan sulfate proteoglycans. Annu Rev Biochem 68: 729-77

42. Germi R, Crance JM, Garin D, et al (2001) Rôle des glycosaminoglycanes dans l'adsorption des virus sur les cellules-hôtes. Virologie 5:255-63

43. Nair MP, Kandaswami C, Mahajan S, et al (2002) Grape seed extract proanthocyanidins downregulate HIV-1 entry coreceptors, $\mathrm{CCR} 2 \mathrm{~b}, \mathrm{CCR} 3$, and CCR5 gene expression by normal peripheral blood mononuclear cells. Biol Res 35:421-31

44. You HL, Huang CC, Chen CJ, et al (2018) Anti-pandemic influenza $\mathrm{A}(\mathrm{H} 1 \mathrm{~N} 1)$ virus potential of catechin and gallic acid. J Chin Med Assoc 81:458-68

45. Yu C, Yan Y, Wu X, et al (2009) Anti-influenza virus effects of the aqueous extract from Mosla scabra. J Ethnopharmacol 127:280-5

46. Lee HJ, Lee YN, Youn HN, et al (2012) Anti-influenza virus activity of green tea by-products in vitro and efficacy against influenza virus infection in chickens. Poult Sci 91:66-73

47. Yamada H, Takuma N, Daimon T, Hara Y (2006) Gargling with tea catechin extracts for the prevention of influenza infection in elderly nursing home residents: a prospective clinical study. J Altern Complement Med 12:669-72

48. Matsumoto Y, Kaihatsu K, Nishino K, et al (2012) Antibacterial and antifungal activities of new acylated derivatives of epigallocatechin gallate. Front Microbiol 3:53

49. Xu J, Xu Z, Zheng W (2017) A review of the antiviral role of green tea catechins. Molecules 22:1337

50. Ide K, Kawasaki Y, Kawakami K, Yamada H (2016) Antiinfluenza virus effects of catechins: a molecular and clinical review. Curr Med Chem 23:1-11

51. Kitazato K, Wang Y, Kobayashi N (2007) Viral infectious disease and natural products with antiviral activity. Drug Discov Ther $1: 14-22$

52. Bahramsoltani R, Sodagari HR, Farzaei MH, et al (2015) The preventive and therapeutic potential of natural polyphenols on influenza. Expert Rev Anti Infect Ther 14:57-80

53. Chaouche TM, Haddouchi F, Atik-Bekara F, et al (2015) Antioxidant, haemolytic activities and HPLC-DAD-ESI-MSn characterization of phenolic compounds from root bark of Juniperus oxycedrus subsp. oxycedrus. Ind Crop Prod 64:182-7 